\title{
NOTE ON A FORMULA ASSOCIATED WITH THE PATH OF A RAY THROUGH A PRISM.
}

BY

H. S. UHLER.

Professor Southall has recently published a trigonometrical formula for the calculation of the angle of incidence of a ray which traverses a prism in a principal section and emerges under a prescribed angle of deviation. ${ }^{1}$ With regard to this formula he makes the following comment: "It is possible that it may be arranged in a form more convenient for logarithmic computation." More than seven years ago the present writer published the solution of this problem for the case of a ray traversing a prism obliquely. ${ }^{2}$ Accordingly it may be of practical interest to present, in this place, the logarithmic formulæ as simplified for a principal plane.

The angle $\alpha_{0}$ is first calculated from the equation

$$
\sin \alpha_{0}=n \sin \frac{\mathrm{r}}{2} \beta,
$$

where $\alpha_{0}$ and $\beta$ denote respectively the angle of incidence corresponding to minimum deviation, and the refracting angle of the prism.

An auxiliary angle $\phi$ is next computed from the equation

$$
\tan \phi=\tan c \cdot \sqrt{ }\left\{\sin \left[\frac{\mathrm{I}}{2}(\varepsilon+\beta)+a_{0}\right] \sin \left[\frac{\mathrm{r}}{2}(\varepsilon+\beta)-a_{0}\right]\right\},
$$

where $c$ and $\epsilon$ symbolize respectively the critical angle, and the prescribed angle of deviation. If more convenient, $\tan c$ may be replaced by

$$
\mathrm{I} / \sqrt{(n+\mathrm{I})(n-\mathrm{I})} .
$$

The two values of the angle of refraction, $\alpha^{\prime}$, may now be obtained by the aid of the following formula:

$$
\tan \left(\alpha^{\prime}-\frac{I}{2} \beta\right)= \pm \sin \phi \cot \frac{I}{2}(\varepsilon+\beta) .
$$

'James P. C. Southall: "Note on the path of a ray through a prism in a principal section." Jour. Opt. Soc., 4, p. 283, 1920.

${ }^{3} \mathrm{H}$. S. Uhler: "On the deviation produced by prisms." Am. Jour. Sci., 35, p. 396, I913. 
Jan., 192I.] Path of a Ray Throvgh a Prism.

Finally

$$
\sin \alpha=n \sin \alpha^{\prime} .
$$

In the illustrative case, taken by Professor Southall, where $n=\mathrm{I} \cdot 5, \beta=60^{\circ}$, and $\epsilon=40^{\circ}$ we find

$$
\begin{aligned}
& a_{0}=48^{\circ} 35^{\prime} 25.4^{\prime \prime} \\
& \phi=7^{\circ} 56^{\prime} 28.7^{\prime \prime} \\
& \alpha^{\prime}-\frac{1}{2} \beta= \pm\left(\begin{array}{lll}
6^{\circ} & 36^{\prime} & 45.8^{\prime \prime}
\end{array}\right) \\
& \left(a^{\prime}\right)_{+}=36^{\circ} \quad 36^{\prime} 45.8^{\prime \prime} \\
& \left(a^{\prime}\right)_{-}^{+}=23^{\circ} \quad 23^{\prime} \quad \mathrm{I} 4.2^{\prime \prime} \\
& (a)_{+}=63^{\circ} 27^{\prime} 27.7^{\prime \prime} \\
& (a)_{-}^{+}=36^{\circ} 3^{\prime} \quad 32.3^{\prime \prime}
\end{aligned}
$$

The numerical values of $\alpha$ just given confirm those of Professor Southall absolutely.

Sloane Physics Laboratory,

YALE UNIVERSITY,

Nov. $29,1920$. 